\title{
Distribusi Horizontal Zooplankton Berdasarkan Salinitas Di Perairan Bonang Kabupaten Demak, Indonesia
}

\author{
Bayu Khrisna Yudhatama*, Sri Redjeki, Chrisna Adhi Suryono \\ Departemen IImu Kelautan, Fakultas Perikanan dan IImu Kelautan, Universitas Diponegoro \\ JI. Prof.H.Soedarto S.H, Tembalang,Semarang, Jawa Tengah 50275 Indonesia \\ E-mail : bayuyudhatama97@gmail.com
}

\begin{abstract}
ABSTRAK: Zooplankton merupakan salah satu biota yang sensitif akan perubahan karakteristik perairan. Zooplankton sering dijadikan indikator terhadap kondisi ekologis suatu perairan. Tujuan dalam penelitian ini yaitu untuk mengetahui Distribusi zooplankton dan pengaruh perbedaan salinitas pada distribusi zooplankton di Perairan Bonang Kabupaten Demak. Lokasi penelitian dibagi menjadi tiga stasiun yaitu Stasiun A (Sungai), Stasiun B (Muara), Stasiun C (Laut). Sampel diambil dengan plankton net di ketiga stasiun tersebut dengan tiga kali pengulangan dan tiga waktu pengulangan di setiap stasiunnya. Hasil penelitian ini ditemukan 20 genus zooplankton yaitu Corycaeus sp, Muggiaea sp, Mysis sp, Penaeus sp, Macrobrachium sp, Anisomysis sp, Pleuromamma sp, Thysanopoda sp, Euterpina sp, Undinula sp, Acartia sp, Arcella sp, Acrocalanus sp, Centropages sp, Candacia $\mathrm{sp}$, Halopthilus sp, Paracalanus sp, Metridia sp, Pseudocalanus sp, Emplectonema sp yang termasuk ke dalam 6 Kelas, Keenam kelas tersebut terdiri dari Hydrozoa, Malascostraca, Maxillopoda, Tubulinea, dan Hexanaulipa. Hasilnya nilai $P$ yaitu $0,00008<0,5$ yang berarti salinitas memberi dampak pada distribusi horizontal zooplankton berdasarkan Uji Anova.
\end{abstract}

Kata kunci: Zooplankton; Distribusi; Keanekaragaman; Kesuburan Perairan; Salinitas.

\section{The Horizontal Distribution of Zooplankton Based On Salinity in Bonang Coastal Waters, Demak Indonesia}

\begin{abstract}
Zooplankton is one of the sensitive biota to respond environmental aquatic of changes. Zooplankton is frequently used as an indicator of the ecological conditions of waters. The purpose of this study is to determine the distribution of zooplankton and the effect of differences in salinity on zooplankton distribution in the coastal waters of Bonang Demak Regency. The research location is divided into three stations namely Station $A$ (River), Station B (Estuary), Station $C$ (Marine). Samples were taken with a plankton net at the three stations with three repetitions and three repetitions at each station. The results of this study found 20 genera zooplankton namely Corycaeus sp, Muggiaea sp, Mysis sp, Penaeus sp, Macrobrachium sp, Anisomysis sp, Pleuromamma sp, Thysanopoda sp, Euterpina sp, Undinula sp, Acartia sp, Arcella sp, Acrocalanus $s p$, Centropages sp, Candacia sp, Halopthilus sp, Paracalanus sp, Metridia sp, Pseudocalanus sp, Emplectonema sp included in 6 Classes, The six classes consist of Hydrozoa, Malascostraca, Maxillopoda, Tubulinea, and Hexanaulipa. The result is $P$ value $P=0,00008<0,5$ that meansthe zooplankton distribution is influenced by salinity based on the Anova Test.
\end{abstract}

Keywords: Zooplankton, Distribution, Diversity, water fertility, salinity.

\section{PENDAHULUAN}

Muara Sungai Dero merupakan sungai yang bermuara di pesisir perairan Kecamatan Bonang, Kabupaten Demak. Muara Sungai Dero merupakan pertemuan dari beberapa sungai yang mengalir ke sungai tersebut. Mengalirnya beberapa sungai ke Sungai Doro menyebabkan terjadinya variasi salinitas. Variasi mualai dari salinitas tawar, payau dan asin (laut) hal tersebut diduga menyebakan terjadinya perbedaan jenis zooplankton yang ada karena pengaruh perbedaan salinitas. 
Keberadaan organisme hidup di suatu tempat tehah mengalamai beberapa adaptasi termasuk adaptasi perubahan salinitas (Suryono et al., 2017). Salinitas merupakan salah satu faktor pembetas distribusi organisme di suatu perairan. Demikian juga halnya dengan zooplankton salinitas merupakan faktor pembatas (Faturohman et al., 2016). Namun secara tidak langsung kandungan nutrien dari daratan melalui aliran beberapa sungai tersebut dapat nutrien yang ada. Nutrien seperti nitrat dan fosfat adalah nutrien yang dibutuhkan dan memiliki peran besar terhadap fitoplankton, dan akan berpengaruh ke zooplankton karena fitoplankton adalah sumber makanan dari zooplankton. Zooplankton merupakan biota dengan tingkat pergerakan yang sangat kecil, oleh karena itu zooplankton keberadaan sangat dipengaruhi salinitas. Zooplankton terdapat pada perairan dengan salinitas yang berbeda-beda, mulai dari perairan sungai dengan salinitas yang tawar lalu daerah estuari dengan salinitas pencampuran antara perairan tawar dengan perairan laut hingga laut dengan tingkat salinitas yang tinggi. Hal tersebut dikarenakan tingkat adaptasi yang berbeda pada setiap jenis zooplankton (Hibatul et al., 2013). Salinitas merupakan faktor pembatas bagi distribusi zooplankton diperairan. Penelitian menurut Cartwright et al (2010) zooplakton dengan Kelas Hydrozoa ditemukan pada perairan laut dangkal dengan salinitas yang relatif tinggi, ditemukan beberapa genus seperti Muggiaea sp, Corycaeus sp, Penaeus sp dan lainlain. Penelitian Richter et al. (2001) zooplankton dengan Kelas Malacostraca dan Hoplonemertea cenderung menempati perairan sungai dan muara yang berarus kecil dengan salinitas yang kecil dan sedang, contohnya seperti genus Emplectonema sp, Thysanopoda sp, Pleuromamma sp dan lain-lain dapat ditemukan pada perairan muara. Penelitian Anderson et al. (2016) zooplankton dari Kelas Tubulinea dan Hexanaulipa disebutkan memiliki habitat dilaut lepas dengan salinitas tinggi dan berada pada daerah yang cukup dalam pada kolom air. Genus seperti Candacia sp, Halopthilus sp, Metridia sp dan lain-lain memiliki persebaran pada laut yang bersalinitas tinggi.

Informasi tersebut dapat dijadikan referensi bahwa distribusi zooplankton diperairan dapat berbeda sesuai dengan kondisi perairan termasuk pada perbedaan salinitas. Oleh karena itu, dilakukan penelitian untuk mengetahui distribusi zooplankton berdasarkan salinitas pada daerah lain. Penelitian ini bertujuan untuk mengetahui mengetahui distribusi zooplankton dan pengaruh perbedaan salinitas pada distribusi zooplankton di Perairan Kecamatan Bonang Kabupaten Demak.

\section{MATERI DAN METODE}

Penelitian dilakukan pada bulan Desember 2018 di Perairan Kecamatan Bonang Kabupaten Demak. Materi penelitian meliputi zooplankton yang berupa sampel air yang di ambil di lokasi penelitian. Pengambilan sampel air dilakukan dengan menggunakan plankton net nomor 24 secara vertikal. Cara pengambilan sampel dilakukan pada malam hari pada tiga stasiun yang berbeda dan setiap titik pengambilan sampel dilakukan tiga kali pengulangan. Penentuan titik awal pengambilan sampel ditentukan mulai dari sungai dengan perkiraan kedalaman air sekitar 2 meter agar plankton net tidak menyaring pasir karena kedalaman sungai yang relatif dangkal, kemudian untuk titik selanjutnya ditentukan dengan waktu 5 menit dari titik awal, dan diulang pada stasiun muara dan laut, titik pengambilan sampel tegak lurus dengan garis pantai. Sampel air dimasukan kedalam botol sampel dan diawetkan dengan formalin $4 \%$ untuk selanjutnya di identifikasi. Selanjutnya sampel di identifikasi di laboratorium. Identifikasi sampel zooplankton dilakukan dengan mikroskop dengan perbesaran 100x yang diamati pada Sedgwick-rafter $10 \mathrm{ml}$ dan menggunakan buku identifikasi Illustration of Marine Plankton (Yamaji, 1984). Hasil dari identifikasi dihitung kelimpahannya menggunakan rumus dari Byod (1979). Analisis data meliputi kelimpahan zooplankton untuk mengetahui distribusi zooplankton, kemudian Uji Anova untuk mengetahui pengaruh salinitas pada distribusi zooplankton.

\section{HASIL DAN PEMBAHASAN}

Komposisi zooplankton yang ditemukan di lokasi penelitian ditemukan 20 genus zooplankton yaitu Corycaeus sp, Muggiaea sp, Mysis sp, Penaeus sp, Macrobrachium sp, Anisomysis sp, Pleuromamma sp, Thysanopoda sp, Euterpina sp, Undinula sp, Acartia sp, Arcella sp, Acrocalanus $\mathrm{sp}$, Centropages sp, Candacia sp, Halopthilus sp, Paracalanus sp, Metridia sp, Pseudocalanus sp, 
Emplectonema sp yang termasuk ke dalam 6 Kelas, Keenam kelas tersebut terdiri dari Hydrozoa, Malascostraca, Maxillopoda, Tubulinea, dan Hexanaulipa. Hasil penelitian menunjukkan bahwa Genus Corycaeus sp merupakan yang paling sering ditemukan di tiap stasiun dan setiap waktu pengambilan sampel. Hasil yang didapatkan dalam penelitian ini, genus Corycaeus sp merupakan genus yang paling banyak ditemukan disemua stasiun penelitian dikarenakan sifatnya yang dapat beradaptasi dengan berbagai salinitas.

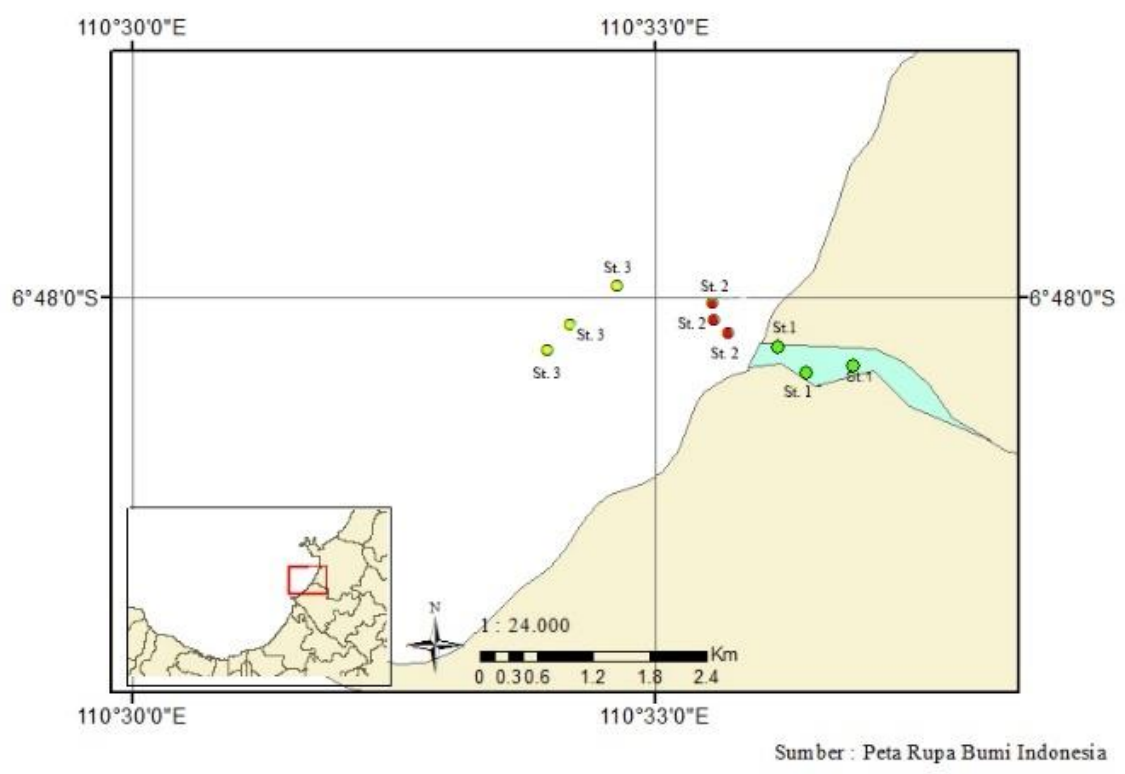

Gambar 1. Peta Lokasi Penelitian di Perairan Dusun Tambakpolo

Tabel 1. Distribusi zooplankton yang Ditemukan di Lokasi Penelitian

\begin{tabular}{|c|c|c|c|c|c|c|c|c|c|c|c|}
\hline \multirow{2}{*}{ No } & \multirow{2}{*}{ Kelas } & \multirow{2}{*}{ Genus } & \multicolumn{3}{|c|}{ Stasiun Sungai } & \multicolumn{3}{|c|}{ Stasiun muara } & \multicolumn{3}{|c|}{ Stasiun laut } \\
\hline & & & 1 & 2 & 3 & 1 & 2 & 3 & 1 & 2 & 3 \\
\hline 1 & \multirow{4}{*}{ Hydrozoa } & Corycaeus & 273 & 277 & 184 & 86 & 108 & 80 & 39 & 7 & 16 \\
\hline 2 & & Muggiaea & 1 & 1 & 0 & 2 & 0 & 0 & 0 & 0 & 0 \\
\hline 3 & & Mysis & 15 & 8 & 11 & 43 & 68 & 83 & 89 & 89 & 186 \\
\hline 4 & & Penaeus & 38 & 32 & 17 & 9 & 7 & 9 & 0 & 0 & 0 \\
\hline 5 & \multirow{5}{*}{ Malacostraca } & Macrobrachium & 6 & 3 & 0 & 0 & 1 & 0 & 0 & 0 & 0 \\
\hline 6 & & Anisomysis & 2 & 0 & 0 & 0 & 0 & 0 & 0 & 0 & 0 \\
\hline 7 & & Pleuromamma & 8 & 12 & 1 & 3 & 3 & 0 & 0 & 0 & 0 \\
\hline 8 & & Thysanopoda & 0 & 2 & 7 & 14 & 14 & 5 & 0 & 0 & 0 \\
\hline 9 & & Euterpina & 3 & 1 & 0 & 0 & 0 & 0 & 0 & 0 & 0 \\
\hline 10 & \multirow[t]{2}{*}{ Maxillopoda } & Undinula & 12 & 1 & 1 & 0 & 0 & 0 & 0 & 0 & 0 \\
\hline 11 & & Acartia & 5 & 2 & 0 & 0 & 0 & 0 & 0 & 0 & 0 \\
\hline 12 & \multirow[t]{4}{*}{ Tubulinea } & Arcella & 6 & 0 & 4 & 0 & 0 & 0 & 0 & 0 & 0 \\
\hline 13 & & Acrocalanus & 2 & 0 & 0 & 0 & 0 & 0 & 0 & 0 & 0 \\
\hline 14 & & Centropages & 0 & 0 & 8 & 2 & 1 & 0 & 34 & 33 & 71 \\
\hline 15 & & Candacia & 0 & 0 & 0 & 0 & 0 & 0 & 59 & 70 & 33 \\
\hline 16 & \multirow[t]{4}{*}{ Hexanaulipa } & Halopthilus & 0 & 0 & 0 & 0 & 0 & 0 & 30 & 17 & 56 \\
\hline 17 & & Paracalanus & 0 & 0 & 0 & 0 & 0 & 0 & 11 & 14 & 0 \\
\hline 18 & & Metridia & 0 & 0 & 0 & 0 & 0 & 0 & 32 & 30 & 16 \\
\hline 19 & & Pseudocalanus & 0 & 0 & 0 & 7 & 22 & 6 & 2 & 0 & 0 \\
\hline \multirow[t]{3}{*}{20} & Hoplonemertea & Emplectonema & 3 & 0 & 1 & 3 & 6 & 5 & 0 & 0 & 0 \\
\hline & Total per titik & & 374 & 339 & 234 & 169 & 230 & 188 & 296 & 260 & 378 \\
\hline & Total 3 Stasiun & & & 947 & & & 587 & & & 934 & \\
\hline
\end{tabular}


Pada stasiun sungai, zooplankton dengan Kelas Hydrozoa dan Malacostraca mendominasi dengan jumlahnya yang lebih banyak dari Kelas yang lain dan genus yang ditemukan yang paling banyak adalah Corycaeus sp dan Penaeus sp, dengan itu dapat dikatakan bahwa dari Kelas Hydrozoa dan Malacostraca dapat beradaptasi pada salinitas yang tawar. Kemudian pada stasiun muara zooplankton dengan kelas Maxillopoda, Tubulinea dan Hoplonemertea ditemukan dengan jumlah yang banyak dibandingkan di stasiun lain dengan itu dapat dikatakan bahwa pada Kelas ini tingkat adaptasi akan salinitas tinggi ada, dikarenakan zooplankton yang ditemukan pada daerah ini dapat hidup pada salinitas yang lebih tinggi. Kemudian pada stasiun laut ditemukan dari Kelas Hexanaulipa, dapat dikatakan zooplankton pada Kelas Hexanaulipa merupakan zooplankton dengan distribusi pada daerah salinitas yang tinggi yaitu dilaut. Oleh karena itu dapat dikatakan bahwa disetiap Kelas yang ditemukan diberbagai stasiun memiliki distribusi yang berbeda sesuai dengan tingkat salinitas yang berbeda (Hutabarat et al., 2014).

Genus Corycaeus sp dan Mysis sp dapat ditemukan pada lautan lepas dengan arus yang rendah, dapat berpindah sesuai arus yang berada pada suatu perairan, biasanya ditemukan mendominasi suatu daerah. Pada hasil penelitian ini ditemukan genus ini dengan mendominasi setiap perairan yang diteliti dari sungai, muara hingga laut (Radhika et al., 2014). Genus Muggiaea $\mathrm{sp}$ terdistribusi pada dua jenis perairan dengan salinitas yang berbeda, salinitas yang rendah diperairan tawar dan salinitas yang tinggi. Berdasarkan hasil yang ditemukan genus ini pada daerah salinitas rendah diperairan tawar distasiun sungai (Blackett, 2015). Genus Penaeus sp ini ditemukan diperairan dangkal, diduga genus ini ditemukan kerana banyaknya bekas tambak yang berada pada sepanjang sungai hingga muara. Genus lain yang dapat ditemukan sama dengan genus ini adalah genus Macrobrachium sp, Anisomysis sp, Pleuromamma sp dan Thysanopoda sp. (Li, 2015). Sedangkan genus seperti Centropages sp, Candacia sp, Halopthilus sp, Paracalanus sp, dan Metridia sp dapat ditemukan dilaut lepas dengan salinitas yang tinggi dan kedalaman yang relatif dalam. Genus-genus ini dapat terdistribusi karena arus hingga sampai ke perairan dangkal hingga ke muara dan sungai (Zhenseng, 2018).

Ketiga stasiun yaitu sungai, muara dan laut memiliki keanekaragaman yang relatif sama di kisaran 0,7 - 0,8 yang tergolong rendah mendekati sedang, namun yang paling tinggi adalah stasiun satu, dikarenakan jumlah zooplankton yang didapatkan lebih banyak dibandingkan stasiun lain yaitu 20 genus. Dan yang paling kecil adalah stasiun laut karena jumlah yang didapatkan lebih sedikit yaitu 18 genus. Indeks keanekaragaman, keseragaman dan dominasi dapat menjadi salah satu acuan untuk menganalisis dan mengetahui suatu kondisi lingkungan perairan (Endrawati et al., 2007).

Dalam kondisi ini perairan Bonang bisa dibilang kurang baik untuk habitat zooplankton. Hal ini dibuktikan dengan tingginya tingkat dominansi pada daerah tersebut. Kedalaman perairan yang dangkal pada lokasi pengamatan menjadi salah satu faktor rendahnya tingkat keanekaragaman pada perairan tersebut. Bisa dikatakan tingkat distribusi vertikal plankton dengan kondisi perairan yang dangkal kurang bervariasi jika dibandingkan dengan perairan yang dalam. Hal demikian juga pada perairan yang mengalir dengan penyebaran vertikal maka distribusi plankton akan berbeda dengan perairan yang menggenang. Kemampaun zooplankton untuk tetap berada pada suatu kedalaman tertentu dipengaruhi oleh bentuk ukuran dan bentuk tubuhnya. Ada pengurangan tubuh yang disebabkan oleh pengurangan berat skeleton atau cangkok, adanya bahan seperti gelatin dan pemeliharaan keseimbangan tekanan osmotik dengan air laut oleh ion-ion yang ringan seperti sulfat merupakan bentuk adaptsi zooplankton untuk mempertahankan dirinya dari kedalaman tertentu (Thoha, 2007).

Hal ini diakibatkan karena keanekaragaman yang rendah, bahkan diduga jenis yang ditemukan di Kecamatan Bonang Kabupaten Demak tidak benar-benar hidup di daerah perairan tersebut atau hanya terbawa oleh arus dari perairan lain, seperti sifat plankton yang tidak punya daya untuk berenang namun hanya terbawa arus laut untuk berpindah tempat secara horizontal.

Pada perairan Kecamatan Bonang Kabupaten Demak ini terdiri dari sungai, muara hingga laut, oleh karena itu zooplankton akan berbeda pada setiap daerah sesuai dengan salinitas, maka dapat ditentukan distribusi horizontal dari zooplankton tersebut berdasarkan salinitas yang berbeda pada setiap daerah. Air tawar akan ditempati oleh zooplankton dengan tingkat adaptasi pada air tawar yang baik, sedang kan air laut akan ditempati oleh zooplankton dengan tingkat adaptasi dengan air laut dengan baik, lalu pada daerah estuari akan ditempati oleh jenis 
zooplankton yang biasanya pencampuran antara perairan tawar dan perairan laut. Sehingga salinitas dapat menentukan distribusi zooplankton pada suatu daerah. Komposisi dan kelimpahan Zooplankton pada suatu perairan sangat bergantung kepada ketersediaan makanan yaitu fitoplankton. Selain itu salinitas, intensitas cahaya, suhu, kecerahan, $\mathrm{pH}$, dan arus juga mempengaruhi keberadaan zooplankton. Selain itu ketersediaan nutrien pada setiap perairan yang berbeda menyebabkan perbedaan kelimpahan plankton pada daerah-daerah tersebut. Salinitas juga mempengaruhi komposisi zooplankton pada setiap daerah berdasarkan tinggi rendahnya salinitas pada suatu perairan. (Khasanah et al., 2013). Dibandingkan dengan keanekaragaman yang ada pada perairan desa Mangunharjo, Semarang relatif hampir sama, hal ini dikarenakan kondisi perairan yang mirip. Kondisi perairan yang hampir sama membuat keanekaragaman pada dua tempat ini menjadi tidak jauh berbeda, persamaan pada kedua tempat ini adalah terdapat mangrove di sekitar aliran sungai dan muara, kecerahan air yang rendah dan arus yang relatif sama karena sama sama bermuara ke laut jawa yang tidak terlalu besar arusnya, kesamaan lainnya adalah dialiran sungai menjadi aliran pembuangan warga setempat, sehingga air bercampur dengan limbah rumah tangga. Semakin besar nilai keanekaragamannya semakin besar pula beragamnya kehidupan diperairan tersebut, Kandungan nutrien di suatu perairan tidak langsung dibutuhkan oleh zooplankton (Afif et al., 2014).

Setelah dilakukan uji Anova mendapatkan hasil signifikan dari data jumlah plankton berdasarkan salinitas bernilai $\mathrm{P}=0.000088<0.05$ yaitu perbedaan salinitas memberi dampak perbedaan distribusi zooplankton pada perairan Kecamatan Bonang Kabupaten Demak.

\section{KESIMPULAN}

Setiap jenis zooplankton memiliki distribusi pada setiap jenis perairan berdasarkan salinitas. Hubungan antara distribusi horizontal zooplankton dengan salinitas berdasarkan hasil uji ANOVA adalah salinitas memberi dampak perbedaan distribusi zooplankton horizontal di perairan Kecamatan Bonang Kabupaten Demak.

\section{UCAPAN TERIMAKASIH}

Artikel ini merupakan bagian dari skripsi yang berjudul "Distribusi Zooplankton di Perairan Dusun Tambakpolo Desa Purworejo Kecamatan Bonang Kabupaten Demak". Penulis mengucapan terima kasih kepada seluruh pihak yang telah membantu selama penelitian. Kepada reviewer jurnal marine research disampaikan penghargaan atas review yang sangat berharga pada artikel ini.

\section{DAFTAR PUSTAKA}

Afif, A., Widianingsih, \& Hartati, R. 2014. Komposisi dan Kelimpahan Plankton Di Perairan Pulau Gusung Kepulauan Selayar Sulawesi Selatan. Journal of Marine Research. 3(3):324-331.

Anderson, R. 2016. Amoebozoan Lobose Amoebae (Tubulinea, Flabellinea, and Others). Doherty Observatory Journal, 18(3):111-118

Blackett, M. 2015. Population ecology of Muggiaea atlantica (Cnidaria, Siphonophora). University of Southamton Journal. 30(3):159-164

Boyd, C. 1979. Water Quality in Warm Water Fish Pound. Auburn Circle Journal. 18(3):98-108.

Cartwright, P. \& Nawrocki, A.M. 2010. Character Evolution in Hydrozoa. Integrative and Comparative Biology Journal, 50 (3):456-472.

Endrawati, H., Zainuri, M., Kusdiyantini, E., \& Kusumaningrum, H.P. 2007. Struktur Komunitas Copepoda di Perairan Jepara. Ilmu Kelautan: Indonesian Journal of Marine Sciences, 12(4):193-198.

Faturohman, I., Sunarto \& Nurruhwati, I. 2016. Korelasi Kelimpahan Plankton Dengan Suhu Perairan Laut Di Sekitar PLTU Cirebon. Jurnal Perikanan Kelautan Unpad. 7(1):115-122

Hibatul, T., Ritniasih, I. \& Azizah, R. 2013. Struktur Komunitas Zooplankton di Ekosistem Lamun Alami dan Berbagai Lamun Buatan Perairan Teluk Awur Jepara. Journal of Marine Research. 2(4):16-22 
Hutabarat, P.U.B., Redjeki S, \& Hartati, R. 2014. Komposisi Dan Kelimpahan Plankton Di Perairan Kayome Kepulauan Togean Sulawesi Tengah. Journal of Marine Research. 3(4):447-455.

Khasanah, R.I., Sartimbul, A., \& Herawati, E.Y. 2013. Kelimpahan dan Keanekaragaman Plankton di Perairan Selat Bali. IImu Kelautan: Indonesian Journal of Marine Sciences, 18(4):193-202.

Li, Y. 2015. Growth and Survival Variations of Penaeus Monodon From Six Breeding Families. International Journal of Aquaculture BioPublisher. 15(39):11-19 pp.

Pratama, B. B., Hasan, Z., \& Hamdani, H. 2012. Pola Migrasi Vertikal Diurnal Plankton Di Pantai Santolo Kabupaten Garut. Jurnal Perikanan dan Kelautan Unpad. 3 (1) : 81-89.

Putra, A. W., Zahidah \& Lili, W. 2014. Struktur Komunitas Plankton Di Sungai Citarum Hulu Jawa Barat. Jurnal Perikanan dan Kelautan Unpad. 3(4):313-325.

Radhika, R., Bijoynandan, S \& Harikrishnan, M. 2014. Redescription of female specimens of Corycaeus (Corycaeus) crassiusculus Dana and Corycaeus (Onychocorycaeus) catus Dahl (Poicilostomatoida: Corycaeidae) from Kavarathi Atoll, Lakshadweep island, India. Cochin University of Science and Technology Journal. 8(2):92-112.

Richter, S. \& Scholtz, G. 2001. Phylogenetic analysis of the Malacostraca. Blackwell Wissenschafts-Verlag Journal. 39 (3):113-136.

Suryono, C,A., Riniatsih, I., Nuraini, R,A,T., Djunaedi, A., Rochaddi, B. \& Subagiyo., 2017., Ekologi perairan Semarang-Demak: Inventarisasi Jenis Kerang yang ditemukan di dasar peraitan. Jurnal Kelautan Tropis, 20(2):84-89

Thoha, H. 2007. Kelimpahan Plankton Di Ekosistem Perairan Teluk Gilimanuk, Taman Nasional, Bali Barat. MAKARA Journal of Science. 11(1):44-48.

Yamaji, I. 1984. Illustration of Marine Plankton. USFK. pp 75-99. 